\section{a Colonização e a ECONOMIA AC̣UCAREIRA EM CAMPINAS, 1765 A 1829}

Colonization and the sugar economy in Campinas, 1765 to 1829
Paulo Eduardo TEIXEIRA

(D) paulo.teixeira@unesp.br

Universidade

Estadual Paulista Marília, SP, Brasil

\section{RESUMO}

A partir da expansão da lavoura canavieira em São Paulo durante o final do século XVIII e início do século XIX, o povoamento do Oeste foi transformando a fronteira do interior paulista, intensificando a presença humana nessa região. A chegada de pessoas livres e escravas foi o resultado de um processo amplo, em que fatores econômicos, políticos e sociais trouxeram mudanças significativas para a região, transformando-a no eixo principal da economia escravista de São Paulo. A fim de avaliarmos o impacto desse processo colonizador, nosso objetivo foi estudar as estruturas demográficas e a posse de escravos em Campinas, de 1765 a 1829, utilizando como principal fonte documental as Listas Nominativas de habitantes.

Palavras-chave: Povoamento, Trabalho escravo, Agregado, Demografia Histórica, São Paulo.

\begin{abstract}
From the expansion of sugarcane in West São Paulo during the late eighteenth and early nineteenth centuries, the settlement in that region started to transform the State of São Paulo, intensifying the human presence in the countryside region. The arrival of a population of free people and slaves was the result of a broad process in which economic, political, and social factors brought significant changes to the region, making it the main axis of São Paulo economy based on slavery. In order to evaluate the impact of that colonization process, our goal was to study the demographic structures and slave ownership in Campinas, from 1765 to 1829 , using as main documentary source the Nominative Lists of inhabitants.
\end{abstract}

Keywords: Settlement, Slavery, Aggregate, Historical Demography, São Paulo. 


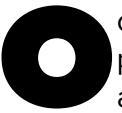

crescimento da produção de açúcar na capitania de São Paulo deveu-se a uma política de exportação bem dirigida pelos capitães generais que aproveitaram a abertura dos portos brasileiros ao comércio exterior no período de 1765 até 1808, e assim procuraram aumentar o movimento dos portos paulistas, especialmente o da vila de Santos, conforme assinalou Petrone (1968, p. 140, 141, 151).

Dois outros aspectos que estimularam a produção de açúcar em São Paulo foram, para Peter Eisenberg (1989, p. 317), a guerra de independência das colônias angloamericanas (1776-82), e a guerra de independência e revolução social na colônia francesa de Saint Domingue (1791-1804). Esses fatos geraram a desorganização do mercado mundial de açúcar e acarretaram uma alta nos preços do produto por vários anos, aguçando, portanto, o interesse dos produtores do Oeste paulista, uma vez que nessa época o açúcar se constituía um dos mais importantes artigos de comércio entre as nações (PETRONE, 1968, p. 140 e 151). Se não podemos negar a influência externa, como sendo fundamental para o desenvolvimento da lavoura comercial, o estabelecimento de uma estrutura portuária e de caminhos de ligação também foram essenciais. Afinal, as notícias que vieram da Europa não poderiam ecoar na capitania paulista se esta não se encontrasse nas condições mínimas para a produção e seu escoamento.

O papel da restauração de São Paulo em 1765, apresentado por Bellotto (1979), foi bem mais amplo do que se costuma imaginar, ultrapassando os desígnios militares e visando ao estabelecimento de um povoamento sólido, através do qual poderia fixar uma economia baseada na agricultura comercial (TEIXEIRA, 2004, p. 39). As sucessivas ações governamentais, quer para promover a concentração da população dispersa, quer para incentivar o crescimento populacional, foram fatores determinantes para a reconstrução da capitania e objetivaram na fundação de diversas vilas e povoados, a começar pelo morgado de Mateus, tais como São José do Paraíba (atual São José dos Campos) em 1767, Itapeva da Faxina, São João Batista do Atibaia e São José do MogyMirim em 1769, Sabaúna em 1770, Itapetininga, Apiaí e Guaratuba em 1771, e Nossa Senhora dos Prazeres de Lajes (atual Lajes - SC) em 1774, as quais prepararam uma infraestrutura de comunicação por meio de caminhos que se expandiram até o início do século XIX. Segundo Bueno (2009, p.273), “Embora esses programas de criação de vilas não dissessem respeito ao território paulista propriamente dito, engendrou nele muitas melhorias e incrementos, em função da necessidade de aperfeiçoar-se continuamente o sistema de comunicação com as novas regiões a ele anexadas".

A criação de vilas continuou após a saída do morgado de Mateus até o final do século XVIII, quando o governador Antonio Manuel de Melo e Castro de Mendonça elevou à condição de vila outras quatro localidades em 1797: São Carlos (antiga freguesia de Nossa Senhora da Conceição das Campinas e atual Campinas), Porto Feliz (antiga Araritaguaba), Nova Bragança (atualmente Bragança Paulista), e Antonina (atual Paraná) (Cf. MÜLLER, 1978, p. 57-66). Assim, "a partir da cidade de São Paulo, uma rede de caminhos irradiava-se em todas as direções” (BUENO, 2009, p. 273). E isso possibilitou a exportação de diversos produtos por meio do porto de Santos, sobretudo porque durante o governo de Bernardo de Lorena (1788-1797) este deixou como 
marca registrada de sua gestão aquilo que Taunay chamou de "a mais notável obra", que foi o calçamento do Caminho do Mar, e com esse feito integrou definitivamente o litoral à capital de São Paulo. Atestam essa transformação vigorosa os mapas de cargas de navios que partiram rumo aos portos europeus, porém o açúcar brasileiro foi agraciado com as altas dos preços, que fizeram dele o principal produto na pauta de exportação da capitania até a primeira metade do século XIX, segundo apontaram Petrone (1968) e Eisenberg (1989). Portanto, o resultado da política iniciada pelo morgado de Mateus em 1765 foi de uma transformação socioeconômica muito significativa, com o surgimento de novos núcleos populacionais, e a passagem de uma economia baseada na agricultura de subsistência a uma economia pautada na exportação de açúcar.

Portanto, nosso objetivo neste artigo é o de demonstrar como o processo de colonização do interior paulista, a partir do caso campineiro, esteve entrelaçado com a intensificação do povoamento e sua relação com a ocupação dos espaços territoriais, voltados ao estabelecimento de uma agricultura agroexportadora, com intenso uso de mão de obra cativa. Para tanto, estaremos trabalhando com as informações contidas nas Listas Nominativas de habitantes - e para Campinas temos um grande número de listas preservadas, que compreendem os anos de 1767 a 1829. ${ }^{1} \mathrm{O}$ aporte teórico-metodológico da Demografia Histórica balizou esse estudo na medida em que fizemos o levantamento populacional de livres e escravos, a partir da leitura e transcrição das Listas Nominativas de habitantes de Campinas por meio do uso do software SPSS, que possibilitou a construção dos gráficos que serão apresentados nesse estudo. Assim, será apresentada uma caracterização da população que veio a se instalar em Campinas, sobretudo dentro de uma perspectiva das atividades econômicas desempenhadas pelas chefias das famílias, uma vez que essa é uma das informações contidas nas Listas de habitantes. Posteriormente, serão tratados alguns aspectos relacionados com a posse de escravos pautados na História Econômica e Social de São Paulo, fechando o artigo com as considerações acerca do processo de colonização que se encerrou com a independência do Brasil.

\section{Estruturas demográficas de Campinas: o bairro, a freguesia e a vila}

A atual cidade de Campinas teve seu princípio a partir da formação de um pouso destinado àqueles que percorriam o caminho que ligava a cidade de São Paulo à região das minas de Goiás. Essa estrada, segundo Saint-Hilaire, se estendia "quase que paralelamente à fronteira ocidental de Minas Gerais", passando por Jundiaí, Campinas, Mogi-Mirim, Mogi-Guaçu, Casa Branca e Franca (SAINT-HILAIRE, 1976, p. 83). Outro viajante, o pastor Kidder, após deixar para trás a capital da Província em 1839 e seguir rumo a Campinas, descreveu a entrada desse caminho da seguinte maneira:

O caminho desenvolvia-se por entre morros e vales, apenas de raro em raro proporcionando uma visão mais ampla. Cada curva da estrada parecia nos levar mais para o âmago de um vastíssimo labirinto repleto de belezas vegetais, apenas levemente tocados, aqui e acolá, pela mão do agricultor (KIDDER, 1980, p. 233). 
Se perto da metade do século XIX o visitante pôde contemplar poucas roças ao longo do caminho, imaginemos o que não teria sido isso por volta de 1740, quando foram distribuídas as primeiras datas de sesmarias na região de Campinas. Para uma ideia mais próxima da realidade passada, o recenseamento da população do "Bayrro do Mato Groço Cam. ${ }^{\circ}$ de Minaz", futura vila de Campinas, informou que a dita localidade pertencia à vila de Jundiaí no ano de 1767, e que era composta por 53 fogos. ${ }^{2}$ Porém, a vida política de Campinas iniciou uma mudança em 1774, quando a mesma atingiu a autonomia religiosa ao estabelecer a freguesia de N. Sra. da Conceição das Campinas, e para, ao final do século XVIII, exatamente no ano de 1797, estabelecer a independência política em relação a Jundiaí, tornando-se uma vila, batizada com o nome de São Carlos. Assim, temos traçado os três períodos aludidos acima, o bairro, que compreendeu o momento anterior a 1774, a freguesia, que se iniciou neste ano e se estendeu até 1797, e finalmente a vila, que findou em 1842, quando então seu nome de origem voltou a ser restaurado, e nasceu a cidade de Campinas.

A Tabela 1 nos dá uma radiografia dos anos de formação e consolidação da vila de Campinas, através da indicação do número de domicílios, da população total encontrada nas Listas Nominativas ou censos, como também são conhecidos estes documentos, e do número médio de habitantes em cada domicílio.

Tabela 1 - População total. Campinas, 1767-1829.

\begin{tabular}{cccc}
\hline Ano* & $\begin{array}{c}\text { N. }{ }^{\circ} \text { Total de } \\
\text { Domicílios }\end{array}$ & $\begin{array}{c}\text { N. }{ }^{\circ} \text { Total de } \\
\text { Habitantes }\end{array}$ & $\begin{array}{c}\text { N. }{ }^{\circ} \text { Médio de Pessoas } \\
\text { por Domicílios }\end{array}$ \\
\hline 1767 & 53 & 268 & 5,1 \\
1770 & 59 & 261 & 4,4 \\
1774 & 57 & 475 & 8,3 \\
1778 & 67 & 448 & 6,7 \\
1782 & 93 & 560 & 6,1 \\
1786 & 111 & 691 & 6,2 \\
1790 & 177 & 1.138 & 6,4 \\
1794 & 249 & 1.862 & 7,5 \\
1798 & 368 & 2.508 & 6,8 \\
1814 & 717 & 5.593 & 7,8 \\
1829 & 950 & 8.545 & 8,9 \\
\hline
\end{tabular}

Fonte: Listas Nominativas de Campinas (Arquivo Edgargd Leuenroth [AEL] - UNICAMP). *Os dados para o ano de 1798 foram coletados em EISENBERG, 1989, p. 358.

Considerando toda a população, verificamos pela Tabela 1 que, mesmo incluindo os escravos, a média de indivíduos por domicílio nunca ultrapassou nove pessoas ao longo de todo o período estudado. Nesse sentido, Campinas, mesmo com a crescente entrada de escravos a partir de 1780, manteve a média de habitantes 
pouco acima da encontrada por Marcílio (2000, p. 97) para toda a capitania de São Paulo. Ao observarmos os anos de $1767 / 70$ e 1774/78, notamos uma ligeira queda no número total de habitantes; entretanto, se levarmos em conta que houve um pequeno aumento do número de domicílios nestes intervalos, é possível afirmar que a queda foi maior, afetando, inclusive, a média de moradores por domicílio, que decresceu respectivamente de 5,1 para 4,4 , e de 8,3 para 6,7 . Isso nos alerta para a mobilidade espacial das pessoas, e até mesmo para o exercício de certas atividades econômicas, como no caso dos tropeiros, visto que os indivíduos permaneciam temporariamente longe de seus lugares de origem. Ademais, encontramos muitos "roceiros", termo que aparece mais na documentação do século XVIII, indicando pessoas que plantam "para o seu gasto", ou ainda aqueles que abrem roças por entre a mata da vegetação nativa, limpando, assim, o terreno por meio do corte de árvores e implantando culturas de ciclos anuais, como faziam também os "agricultores" (ou "lavradores", conforme alguns censos), que, além de plantar para o consumo próprio, comercializavam o excedente, preferencialmente de milho, feijão, trigo, arroz e farinha. Além disso, muitos domicílios de roceiros e agricultores também criavam animais, em especial suínos, produzindo e vendendo o toicinho (FULLER, 1995, p. 52).

Entretanto, como já dissemos, a partir de 1780, as taxas de crescimento populacional foram sempre positivas, e o cálculo da taxa geométrica anual média de crescimento entre 1778 e 1798 foi de 8,9\%, valor muito expressivo se comparado ao de Lorena, no Vale do Paraíba, que alcançou 1,8\% durante o mesmo período, registrado por Marcondes (1998, p. 56). O intervalo precedente demonstrou um ritmo de crescimento menor, e a taxa geométrica anual média entre 1798 e 1829 foi de 4,1\%, o que ainda assim revelou aumento significativo da população, sobretudo a escravizada, conforme pode ser observado no Gráfico 1.

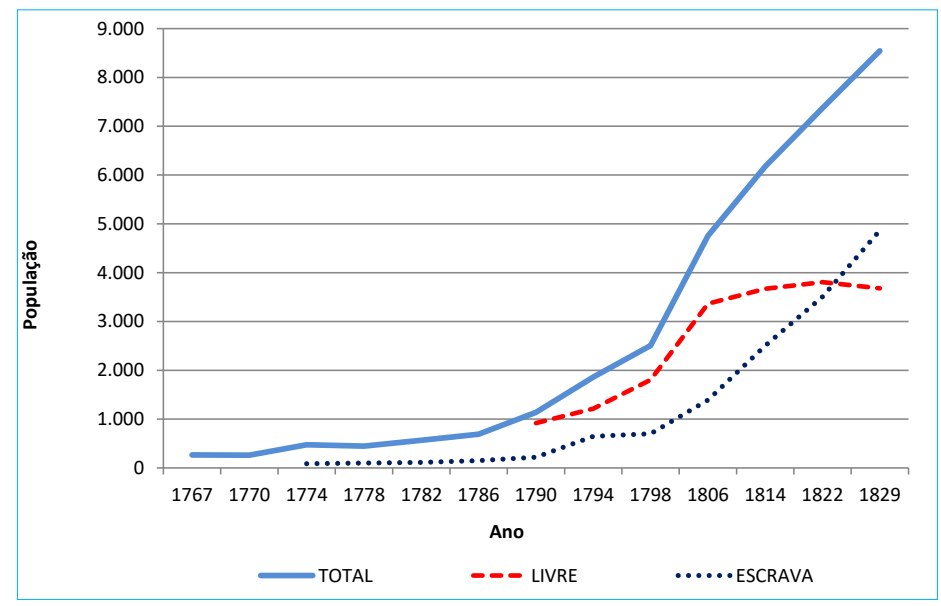

Gráfico 1 - População, por condição social. Campinas, 1767-1829.

Fonte: Listas Nominativas de Campinas (AEL - UNICAMP). 
A partir da última década do século XVIII, Campinas passou a ter um crescimento populacional cada vez maior; no entanto, cabe frisar que, em grande medida, isso se deveu à expansão da lavoura canavieira, atraindo pessoas de condição social livre, e a uma elite agrária, que foi responsável pela compra de cativos na região, e assim abriu espaço para uma nova modalidade de atividade produtiva, a do cultivo da canade-açúcar, a fabricação do açúcar e sua exportação para os mercados europeus. Vejamos os dados da Tabela 2.

Tabela 2 - Distribuição da população total por condição social. Campinas: $1774,1794,1814$ e 1829

\begin{tabular}{ccccc}
\hline \multirow{2}{*}{ Ano } & \multicolumn{4}{c}{ Condição Social } \\
\cline { 2 - 5 } & \multicolumn{3}{c}{ Livres } & \multicolumn{3}{c}{ Escravos } \\
\cline { 2 - 5 } & Números & $\%$ & Números & $\%$ \\
\hline 1774 & 388 & 81,7 & 87 & 18,3 \\
1794 & 1.364 & 73,3 & 498 & 26,7 \\
1814 & 3.700 & 66,2 & 1.893 & 33,8 \\
1829 & 3.746 & 43,8 & 4.799 & 56,2 \\
\hline
\end{tabular}

Fonte: Listas Nominativas de Campinas (AEL - UNICAMP).

Cabe notar que de 1798 até 1836 "a população do Oeste paulista cresceu muito mais vertiginosamente que a capitania como um todo, chegando a triplicar o seu contingente humano", afirmou Bacellar (1997, p.32). Assim, a entrada de livres foi muito importante para o crescimento demográfico da vila campineira, pelo menos até 1814, quando então a mesma ficou estagnada em relação ao aumento relativo da população cativa, que foi paulatinamente se tornando mais expressivo, a ponto de esse grupo se tornar majoritário em 1829 (TEIXEIRA, 2004, p. 116). Sobre esse momento Slenes (1998, p.17) afirmou que "açúcar e escravidão rapidamente tornaram-se praticamente 'sinônimos' em Campinas e o crescimento da população cativa foi explosivo: em torno de $18 \%$ ao ano entre 1789 e 1801, e $5 \%$ ao ano entre 1801 e $1829 "$.

Essas transformações indicadas acima proporcionaram mudanças significativas nas principais atividades exercidas pelos chefes de domicílio entre 1814 e 1829, e notamos que um grande número de agricultores e lavradores deixou de exercer essa atividade. Em 1814, eles somavam 291 chefes de domicílio, correspondendo a 55,3\% do total que havia declarado sua ocupação, sendo que, em 1829, não chegaram a 31\%, com 167 chefes de domicílio. Ao comentar esse movimento em declínio, do número de fogos de agricultores em face do aumento do número de domicílios, Valter Martins (1996, p.38) sugeriu que "o crescimento da população caminhou em direção a outras atividades que não a agrícola”, mas mesmo assim em seu estudo conseguiu demonstrar que ao menos uma pequena parcela de agricultores conseguiu enriquecer ao longo de vários anos, vindo não somente a possuir escravos, como a ingressarem na produção de açúcar. 
Para ilustrar esse processo, recorremos ao caso do capitão e comandante da vila, o senhor Raymundo Alvares dos Santos Prado, natural de Jundiaí. Em 1797, vivia em sua propriedade com a esposa e três filhos, seis pessoas agregadas, além de mais seis escravos: o casal Rodrigo (40 anos, Mina) e Ifigênia (39 anos, criola), Domingos (35 anos, Benguela), João (37 anos, Benguela), Ignacio (14 anos, pardo) e Vicencia (25 anos, parda). Dois anos depois, sua propriedade produzia "mantimentos para a sua casa e juntamente cana de partido", com o auxílio do braço escravo dos seis cativos mencionados e mais José, um jovem de 16 anos. A Lista Nominativa de 1800 revelou que sua produção de cana lhe rendeu 100 arrobas de açúcar branco, 40 de redondo e 10 de mascavo. ${ }^{3}$

Outro exemplo foi o do alferes Domingos da Costa Machado, que em 1803 possuía dois casais de cativos, José, 35 anos com Maria, 24 anos, e Francisco, 23 anos, com Maria de 18 anos. Além desses quatro escravos, tinha também mais três jovens escravos, Francisco, João e Antonio, respectivamente com idade de 24, 23 e 21 anos, sendo todos eles de origem africana. O alferes era natural de Campinas e casado com Manuela de Camargo, nascida em Cotia, uma das localidades de onde vieram várias pessoas da elite agrária que se estabeleceu ao longo do ciclo canavieiro. Nessa ocasião, tanto Domingos quanto sua esposa Manuela tinham 29 anos, e eram pais de quatro filhos: Ignacio, José, Maria e Ana, sendo o mais velho com sete anos e a mais nova com seis meses. Sua atividade econômica era de "agricultor" e tinha colhido 300 alqueires de milho e 20 de feijão. No entanto, no ano seguinte, ele declarou uma produção de 500 arrobas de açúcar, indicando que estava entrando em um negócio muito lucrativo, uma vez que em 1814, agora com 38 anos, segundo a Lista Nominativa desse ano, havia sido elevado à posição de tenente miliciano e se tornado um senhor de engenho com 12 escravos, produzindo 400 arrobas de açúcar, 30 canadas de aguardente, 400 alqueires de milho e 70 de feijão. Em 1829, quando se encontrava já viúvo, alçara ao posto de sargento mor de milícias, e sua propriedade escrava era constituída de 48 pessoas. ${ }^{4}$

Nesse sentido, Cláudia Fuller (1995, p. 78) aventou a hipótese de que com "o crescimento da vila, e consequentemente de seu mercado de serviços teria influído na entrada dos agricultores em outras áreas profissionais", sobretudo a partir da segunda década do século XIX. Houve, portanto, aumento do número de agricultores que passaram a trabalhar no transporte de mercadorias, e com isso atividades ligadas a esse ramo de negócio levaram muitos agricultores a se tornarem tropeiros, camaradas de tropa, arreadores, seleiros, negociantes de animais. Também cresceu o número de negociantes e daqueles que viviam de costura, venda, agências, prestação de serviços e jornais de escravos. No entanto, toda essa mudança foi operada pelo estabelecimento da economia açucareira, donde os senhores de engenho foram os grandes responsáveis, sobretudo aqueles provenientes de Itu e Jundiaí, pois pelo menos desde o final do século XVIII vieram representantes das principais famílias desse ramo de atividade, estabelecendo laços por meio dos casamentos, como demonstrou Bacellar (1997, p. 102, 104 e 107) ao estudar as alianças matrimoniais da elite do Oeste paulista. Nos dizeres do autor: 
A posição de destaque de Itu no contexto migratório da elite se deveu ao fato de a vila ter sido, no período que nos interessa, a de maior população em todo o Oeste e, por consequência, a de maior elite em termos numéricos. Por outro lado, o pioneirismo de Itu manteve-se na dianteira da produção do Oeste somente até o início do século XIX, quando a vila começou a entrar em decadência perante a concorrência de Campinas e das novas vilas rumo ao sertão. (BACELLAR, 1997, p. 107)

Em outro estudo, que focalizou a questão da herança em Campinas durante esse mesmo período, Dora Paiva da Costa (1997, p. 116) notou que "havia tendência à alta da pressão de recursos fundiários no município em foco, associada à presença da fronteira aberta, ao aumento do grau de capitalização da agricultura que se tornava mais mercantilizada”. Assim, a terra tornava-se mais valorizada, e não apenas as áreas de solo bom, mas aquelas destinadas ao fornecimento de madeira para as caldeiras dos engenhos. A concentração de terras pelos grandes senhores de engenho passava não só pelo fato de quererem a ampliação da produção, mas também como forma de garantirem os meios para se efetivar essa produção (MILLER, 1995).

Observando a Tabela 3, vemos que, do total de 353 produtores de milho em 1814, 314 eram agricultores, sendo que a maioria deles (162) representava um grupo de pessoas que detinha uma produção anual acima de 100 alqueires. Para termos uma ideia disso, basta dizer que, no ano de 1822, em Rio Claro, Warren Dean calculou que a maioria dos agricultores plantava em média 83 alqueires, enquanto em Campinas a média desse grupo era de 210 alqueires. A produção total da vila em 1814, indicada pelos censos, foi de 50.586 alqueires. $^{5}$

Tabela 3 - Produção de milho dos chefes de domicílio pelo tipo de atividade. Campinas, 1814.

\begin{tabular}{lccccc}
\hline \multirow{2}{*}{ Atividade } & \multicolumn{5}{c}{ Faixa de Produção (Alqueires) } \\
\cline { 2 - 5 } & $1-49$ & $50-99$ & $100-999$ & +1000 & TOTAL \\
\hline Sr. Engenho & 0 & 1 & 20 & 2 & 23 \\
Administrador & 0 & 0 & 3 & 0 & 3 \\
Planta Cana & 0 & 2 & 3 & 0 & 5 \\
Agricultor & 72 & 80 & 162 & 0 & 314 \\
Lavrador & 4 & 2 & 1 & 0 & 7 \\
Indefinido & 0 & 0 & 1 & 0 & 1 \\
Total de & 76 & 85 & 190 & 2 & 353 \\
Produtores & $21,5 \%$ & $24 \%$ & $53,9 \%$ & $0,6 \%$ & $100 \%$ \\
Total da & 2.198 & 4.898 & 39.890 & 3.600 & 50.586 \\
Produção & $4,3 \%$ & $9,7 \%$ & $78,8 \%$ & $7,2 \%$ & $100 \%$ \\
\hline
\end{tabular}

Fonte: Listas Nominativas de Campinas (AEL - UNICAMP). 
Comentando acerca da vinda da família real ao Brasil, Eisenberg (1989) disse que o Rio de Janeiro tornou-se um importante centro consumidor do açúcar de Campinas, e, em estudo mais recente, Marcondes afirmou o seguinte:

Outros gêneros nacionais mereceram destaque na pauta de importação do porto carioca. [...] Diversos produtos somaram valores próximos a mil contos: couros, algodão, carnes, feijão e farinha de mandioca. Por fim, ao redor de quinhentos contos encontravam-se o milho, o arroz e o toucinho. [...] Além da dinâmica propiciada pela sede administrativa e política da colônia e, mais tarde do Império, um dos elementos determinantes do crescimento da cidade do Rio de Janeiro foi o estabelecimento de fortes vínculos mercantis com diversas áreas cafeeiras em expansão. [...] A própria capitania fluminense também apresentou uma produção açucareira e de aguardente dinâmica ao final do século XVIII e no início do XIX, fortalecendo sua economia. (MARCONDES, 2005, p. 148)

Assim, podemos perceber que o cenário internacional do final do século XVIII favoreceu mudanças que impactaram também o mercado interno no Brasil, e os senhores de engenho não ficaram alheios a essas mudanças, cultivando em larga escala alguns desses produtos, como o milho, feijão e arroz, uma vez que eram produtos extremamente valiosos no cardápio diário da população. Além disso, não podemos esquecer que, além do uso do milho na alimentação humana, temos que destacá-lo também como produto fundamental para a criação de animais.

A diminuição da produção de milho em 1829 (Cf. Tabela 4) esteve diretamente relacionada à queda do número de produtores, uma vez que a média de produção por domicílio permaneceu em torno de 150 alqueires. A saída dos senhores de engenho desse grupo de plantadores de milho não quer dizer que tenham parado de cultivar o produto, mas que, nesse momento, a sua produção era apenas destinada ao gasto, pois, como veremos, foi na produção do açúcar que se concentrou a atenção deles.

Tabela 4 - Produção de milho dos chefes de domicílio pelo tipo de atividade. Campinas, 1829.

\begin{tabular}{|c|c|c|c|c|c|}
\hline \multirow{2}{*}{ Atividade } & \multicolumn{4}{|c|}{ Faixa de Produção (Alqueires) } & \multirow{2}{*}{ Total } \\
\hline & $1-49$ & $50-99$ & $100-999$ & +1000 & \\
\hline Agricultor & 14 & 20 & 36 & 0 & 70 \\
\hline Lavrador & 10 & 10 & 10 & 0 & 30 \\
\hline Tropeiro & 0 & 0 & 7 & 1 & 8 \\
\hline Venda & 0 & 1 & 2 & 0 & 3 \\
\hline \multirow{2}{*}{$\begin{array}{l}\text { Total de } \\
\text { Produtores }\end{array}$} & 24 & 31 & 55 & 1 & 111 \\
\hline & $21,6 \%$ & $27,9 \%$ & $49,6 \%$ & $0,9 \%$ & $100 \%$ \\
\hline \multirow{2}{*}{$\begin{array}{l}\text { Total da } \\
\text { Produção }\end{array}$} & 709 & 2.055 & 12.045 & 2.000 & 16.809 \\
\hline & $4,2 \%$ & $12,3 \%$ & $71,6 \%$ & $11,9 \%$ & $100 \%$ \\
\hline
\end{tabular}

Fonte: Listas Nominativas de Campinas (AEL - UNICAMP). 
Assim como o milho, o mesmo aconteceu com o feijão e o arroz, embora a média de produção por domicílio tenha ficado estável. Eram alguns poucos senhores de engenho os responsáveis pela maior parcela da produção, e neste caso a saída de agricultores desse grupo de plantadores teve impacto menor no total da produção.

Quanto ao açúcar, o principal produto de comercialização, no início do século XIX em São Paulo, era realizado por 58 produtores em 1814, sendo que alguns engenhos eram dirigidos por administradores de senhores de engenho que moravam em outras localidades, como São Paulo e Itu. Por exemplo, o senhor Joaquim Barbosa, de 32 anos de idade, era o administrador do engenho do Coronel Luis Antonio de Souza, e produziu 500 arrobas de açúcar alvo, 320 de mascavo e 100 arrobas de açúcar redondo, e tinha uma escravaria de 46 pessoas, sendo 27 solteiros, e destes seis menores de 12 anos de idade, 18 casados e uma viúva. ${ }^{6}$ A Tabela 5 mostra que a maioria dos produtores de açúcar era composta de pequenos produtores, isto é, sua produção total não atingia 500 arrobas de açúcar, e dentre eles figuravam 26 senhores de engenho e 6 que plantavam cana. Mas eram apenas 14 domicílios os responsáveis por mais da metade da produção do açúcar, que chegou a 32.910 arrobas, o equivalente a $483.777 \mathrm{~kg} .^{7}$

Tabela 5 - Produção de açúcar dos chefes de domicílio pelo tipo de atividade. Campinas, 1814.

\begin{tabular}{lcccc}
\hline \multirow{2}{*}{ Atividade } & \multicolumn{3}{c}{ Faixa de Produção (Alqueires) } & \multirow{2}{*}{ Total } \\
\cline { 2 - 4 } & $1-499$ & $500-999$ & $1.000-4.999$ & \\
\hline Sr. Engenho & 26 & 9 & 11 & 46 \\
Administrador & 0 & 3 & 3 & 6 \\
Planta Cana & 6 & 0 & 0 & 6 \\
\hline \multirow{2}{*}{ Total de Produtores } & 32 & 12 & 14 & 58 \\
\hline \multirow{2}{*}{ Total da Produção } & $55,1 \%$ & $20,7 \%$ & $24,2 \%$ & $100 \%$ \\
\cline { 2 - 4 } & 7.040 & 8.570 & 17.300 & 32.910 \\
\hline
\end{tabular}

Fonte: Listas Nominativas de Campinas (AEL - UNICAMP).

Em 1829, a produção de açúcar alvo, redondo e mascavo chegou a 120.195 arrobas, ou seja, em 15 anos a produção quase quadruplicou. A Tabela 6 ilustra a produção desse grupo de produtores, com destaque para as maiores fazendas que em número de 38 produziam 81,6\% de todo o açúcar de Campinas, e dentre esses figurou o jovem senhor de engenho Antonio Manuel Teixeira, de apenas 28 anos, natural da própria vila campineira, solteiro, que contava com 138 cativos para produzir 7.000 arrobas de açúcar. Essa produção foi seguida pelo processamento do açúcar em duas fazendas do Coronel Francisco Ignácio de Souza Queiroz, sendo a primeira administrada por João Bueno da Silva, e a segunda por José Francisco, produzindo 4.950 arrobas e 5.000 arrobas, respectivamente. ${ }^{8}$ 
Tabela 6 - Produção de açúcar dos chefes de domicílio pelo tipo de atividade. Campinas, 1829.

\begin{tabular}{|c|c|c|c|c|c|}
\hline \multirow{2}{*}{ Atividade } & \multicolumn{4}{|c|}{ Faixa de Produção (Arrobas) } & \multirow{2}{*}{ Total } \\
\hline & $1-499$ & $500-999$ & $1.000-4.999$ & +5.000 & \\
\hline Sr. Engenho & 19 & 21 & 32 & 1 & 73 \\
\hline Administrador & 0 & 2 & 4 & 1 & 7 \\
\hline Planta Cana & 1 & 0 & 0 & 0 & 1 \\
\hline Jorn. Escravos & 1 & 0 & 0 & 0 & 1 \\
\hline Agricultor & 1 & 0 & 0 & 0 & 1 \\
\hline \multirow{2}{*}{$\begin{array}{l}\text { Total de } \\
\text { Produtores }\end{array}$} & 22 & 23 & 36 & 2 & 83 \\
\hline & $26,5 \%$ & $27,7 \%$ & $43,4 \%$ & $2,4 \%$ & $100 \%$ \\
\hline \multirow{2}{*}{$\begin{array}{l}\text { Total da } \\
\text { Produção }\end{array}$} & 6.077 & 15.970 & 86.148 & 12.000 & 120.195 \\
\hline & $5,1 \%$ & $13,3 \%$ & $71,7 \%$ & $9,9 \%$ & $100 \%$ \\
\hline
\end{tabular}

Fonte: Listas Nominativas de Campinas (AEL - UNICAMP).

Analisando os níveis de produção, vimos que no período entre 1814 e 1829 Campinas passou por um processo de concentração de riqueza, e que, no caso específico dos pequenos produtores, estes tiveram uma queda na participação do total da produção de açúcar. Os pequenos fabricantes, que eram maioria $(55,1 \%)$ em 1814 , passaram a constituir uma parcela mais restrita desse já seleto grupo, com $26,5 \%$ dos produtores de açúcar em 1829. Ao comparar a produção, a diferença é ainda maior, pois em 1814 eles eram responsáveis por $21,4 \%$ da produção, ao passo que em 1829 significaram apenas $5,1 \%$, ou seja, eram os 38 maiores produtores $(45,8 \%)$ os responsáveis por pouco mais de $80 \%$ da produção.

Tornar-se um senhor de engenho, a partir de então, parece que foi algo extremamente difícil para os agricultores. A época dos "plantadores de partido", de roceiros que com poucos escravos iniciavam uma plantação de cana, ficara no passado, no final do século XVIII. Talvez por isso houvesse apenas um agricultor entre aqueles que produzia açúcar. Nesse momento, o fabrico do açúcar "dependia de uma dotação prévia de capital, mormente instalações do engenho e escravaria” (MOTTA; NOZOE, 1994, p. 265), recursos que apenas famílias mais abastadas possuíam.

\section{A posse de escravos em Campinas}

O estudo das atividades produtivas desenvolvidas por meio do trabalho escravo, em especial o estabelecimento dos senhores de engenho em Campinas no final do século XVIII até as duas primeiras décadas do século seguinte, leva-nos, necessariamente, ao estudo da posse de escravos, uma vez que essa atividade demandou um aporte cada vez maior de cativos na lavoura canavieira. Diante disso, resta-nos fazer algumas colocações acerca da estrutura escravista que foi instalada em Campinas nesse momento histórico. 
Tabela 7 - Indicadores populacionais. Campinas, 1774, 1794, 1814 e 1829.

\begin{tabular}{|c|c|c|c|c|}
\hline \multirow{2}{*}{ Estrutura populacional } & \multicolumn{4}{|c|}{ Ano } \\
\hline & 1774 & 1794 & 1814 & 1829 \\
\hline \% de Livres na população total & 71,4 & 65,3 & 54,1 & 38,4 \\
\hline \% de Agregados na população total & 10,1 & 8,0 & 10,9 & 4,6 \\
\hline \% de Escravos na população total & 18,5 & 26,7 & 33,8 & 56,2 \\
\hline \% de Escravos dos agregados na população total & 0 & 0 & 1,2 & 0,8 \\
\hline N. ${ }^{\circ}$ Médio de pessoas livres por domicílio & 6,0 & 4,8 & 4,2 & 3,5 \\
\hline N. ${ }^{\circ}$ Médio de agregados por domicílio* & 2,6 & 2,4 & 3,3 & 2,6 \\
\hline N. ${ }^{\circ}$ Médio de escravos por domicílio* & 3,5 & 6,7 & 9,4 & 14,7 \\
\hline N. ${ }^{\circ}$ Médio de escravos dos agregados por domicílio* & 0 & 0 & 9,2 & 7,3 \\
\hline N ${ }^{\circ}$ Médio de pessoas por domicílio & 8,4 & 7,5 & 7,8 & 8,9 \\
\hline
\end{tabular}

Fonte: Listas Nominativas de Campinas (AEL - UNICAMP).

Nota: * Para a obtenção do número médio, foram considerados apenas os domicílios onde havia a presença de escravos agregados e escravos de agregados.

Verificando alguns indicadores populacionais ao longo de vários anos, constatamos uma proporcional queda do número de pessoas livres dentro da população total, ao passo que o número de escravos seguiu na direção inversa, ou seja, proporcionalmente a sua população foi crescendo, até superar, de forma absoluta, a população de livres (Vide Gráfico 1).

Pelo exposto na Tabela 7, constatamos que o número médio de habitantes camufla um processo de queda na participação da população livre no decorrer dos anos, cuja diminuição chegou ao seu ponto mínimo em 1829, quando grande parte das famílias de livres era constituída de 3 a 4 pessoas em média. A variação decrescente sofrida pela população livre indicou que a sociedade campineira sofreu uma transformação significativa, deixando de ser uma sociedade "rural de autoconsumo" - com um elevado índice de livres -, para ser uma região de "agricultura voltada para a comercialização", em que a presença de escravos, principalmente, tornou-se preponderante (COSTA, 1982, p. 90, 91). ${ }^{9}$

$\mathrm{Na}$ base dessa sociedade, o escravo passou a ganhar maior importância para o estabelecimento de uma economia agrária voltada ao comércio, e em 1814, quando a vila de Campinas não tinha completado vinte anos de existência, a mesma já despontava como uma região com forte presença de mão de obra escrava, e assim em 1829 superava a antiga vila de Itu e muitas outras. ${ }^{10}$

O agregado, por sua vez, foi designado em estudo de Eni de Mesquita como aquele que nada possuía de seu, corroborando inclusive algumas assertivas de alguns viajantes estrangeiros, como Saint Hilaire, que retrataram o agregado dessa mesma forma. Porém, em Campinas foram encontrados alguns poucos indivíduos que viviam 
em domicílios como agregados, porém possuindo alguns escravos, o que demonstra que o termo "agregado" não se destinava a rotular apenas pessoas desafortunadas, mas as que poderiam vir a ser parentes, amigos e até estranhos que se congregavam a um grupo familiar (MESQUITA, 1977, p. 42). Além disso, outro aspecto importante a ser notado foi que o agregado, enquanto mão de obra auxiliar, poderia em uma economia de subsistência ter o seu papel mais valorizado, pois em 1774 a participação desse grupo correspondeu a $50 \%$ da mão de obra escrava, podendo ser disputada por diversos senhores de terras." ${ }^{11}$

Essa desvalorização do papel desempenhado pelo agregado sob o aspecto de mão de obra suplementar numa economia comercial não ocorreu somente em Campinas. Ao ser feita a distribuição da população geral de Itu na qualidade de livres, escravos e agregados, entre os anos de 1773 e 1829, observamos que a participação deste último grupo também foi decrescente, partindo de 10\% para 4\% (MESQUITA, 1977, p.47).

Enfim, a baixa participação dos agregados em 1829 denotou o estabelecimento efetivo da ordem escravocrata na região, impedindo o "processo de socialização que levaria as populações marginais a se integrarem plenamente no mundo que as circundava" (CAMPOS, 1984, p. 44). Em oposição a esse quadro de crescimento do número de escravos, os moradores da cidade de São Paulo encontraram no agregado a solução para ocupar o lugar do escravo, pois segundo propôs Kuznesof (1998, p.229), no decurso do processo de urbanização da cidade, a população agregada proporcionalmente cresceu na composição dos domicílios, saltando de 4,7\% em 1765, para $20,7 \%$ em 1802 e $26 \%$ no ano de 1836 .

Todavia, em Campinas, embora tivesse ocorrido um aumento da população escrava de maneira geral, o que percebemos é que a posse de escravos foi importante fator de diferenciação social e econômica, constituindo em prestígio para os seus detentores, o que vale dizer que a propriedade escrava constituía grande parte de sua riqueza. Assim, ao utilizarmos o índice de Gini para cada um dos anos estudados, notamos o aumento da concentração de riqueza na localidade campineira, expresso pelo aumento do índice de Gini de 0,46 em 1774 para 0,52 em 1794, e de 0,63 em 1814 para 0,67 em 1829.12 Tais informações permitem notar a intensificação do processo de concentração de riqueza na forma de escravos entre o final do século XVIII e início do XIX, momento este em que a lavoura canavieira assumiu importante papel econômico na vila campineira.

Confirmam essa posição os resultados apresentados pela Tabela 8, que mostrou a distribuição porcentual dos escravistas e seus cativos por faixas de tamanho de propriedades. Ao considerarmos os proprietários de pequenas escravarias, ou seja, aqueles com menos de 5 cativos, notamos que os mesmos agregaram a maior parte dos senhores ao longo dos anos selecionados. Entretanto, quando avaliamos a posse de escravos nas mãos desses mesmos senhores, notamos um movimento de queda dos números, representando a perda de importância desse grupo, que em 1774 detinha $50,6 \%$ de toda escravaria, e em 1829 chegou a compor apenas 6,4\%. 
Por outro lado, há o crescimento constante de escravistas com mais de 40 cativos, e este grupo de senhores passou a ser o responsável pela maior concentração de escravos nos anos de 1814 , com $34,4 \%$, e em 1829 , com $55,5 \%$. O número médio de escravos por proprietário para essa mesma faixa correspondeu a 50 cativos em 1814, e 70 em 1829.

Tabela 8 - Distribuição porcentual dos proprietários de escravos e de cativos de acordo com faixas de tamanho dos cativos. Campinas, 1774, 1794, 1814 e 1829.

\begin{tabular}{|c|c|c|c|c|c|c|c|c|}
\hline \multirow{2}{*}{ FTP } & \multicolumn{4}{|c|}{ \% de Proprietários } & \multicolumn{4}{|c|}{ \% de Escravos } \\
\hline & 1774 & 1794 & 1814 & 1829 & 1774 & 1794 & 1814 & 1829 \\
\hline 1 & 24,0 & 16,2 & 19,8 & 21,4 & 6,9 & 2,4 & 2,1 & 1,5 \\
\hline $2-4$ & 60,0 & 39,2 & 39,6 & 26,9 & 43,7 & 15,8 & 11,6 & 4,9 \\
\hline $5-9$ & 12,0 & 18,9 & 16,4 & 16,2 & 22,9 & 17,1 & 11,7 & 7,2 \\
\hline $10-19$ & 0,0 & 20,3 & 8,4 & 14,4 & 0,0 & 39,2 & 12,4 & 13,7 \\
\hline $20-39$ & 4,0 & 4,1 & 9,4 & 9,5 & 26,5 & 14,5 & 27,8 & 17,2 \\
\hline $40 e^{+}$ & 0,0 & 1,3 & 6,4 & 11,6 & 0 & 11,0 & 34,4 & 55,5 \\
\hline Total & 100,0 & 100,0 & 100,0 & 100,0 & 100,0 & 100,0 & 100,0 & 100,0 \\
\hline
\end{tabular}

Fonte: Listas Nominativas de Campinas (AEL - UNICAMP). Obs.: \% = distribuição porcentual.

Quando analisamos a proporção entre homens e mulheres na população escrava, percebemos nitidamente que a vinda de cativos do sexo masculino tornouse preponderante, principalmente a partir de 1794, momento em que os engenhos começaram a proliferar na freguesia, conforme atesta a Tabela 9:

Tabela 9 - Razão de sexo da população escrava pela faixa etária. Campinas: 1778-1829.

\begin{tabular}{lcccccccc}
\hline Razão* & $\mathbf{1 7 7 8}$ & $\mathbf{1 7 8 2}$ & $\mathbf{1 7 8 6}$ & $\mathbf{1 7 9 0}$ & $\mathbf{1 7 9 4}$ & $\mathbf{1 8 0 0}$ & $\mathbf{1 8 1 7}$ & $\mathbf{1 8 2 9}$ \\
\hline-12 & 66 & 47 & 81 & 60 & 89 & 118 & 96 & 103 \\
$12-60$ & 106 & 131 & 123 & 119 & 163 & 213 & 266 & 259 \\
+60 & 300 & 250 & 200 & 350 & 600 & 600 & 411 & 644 \\
\hline Total & 100 & 103 & 108 & 99 & 145 & 194 & 234 & 234 \\
\hline
\end{tabular}

Fonte: Listas Nominativas de Campinas (AEL - UNICAMP) ${ }^{13}$

${ }^{*} A$ razão de sexo define-se como sendo o número de homens por um grupo de 100 mulheres.

Embora houvesse a preferência por escravos do sexo masculino para o trabalho no campo, certo equilíbrio entre os sexos pode ser notado até cerca do ano de 1790 (Cf. Gráfico 2), quando então as razões de sexo atingiram as marcas de 145 em 1794, 194 em 1800, e 234 em 1817 e também em 1829. 


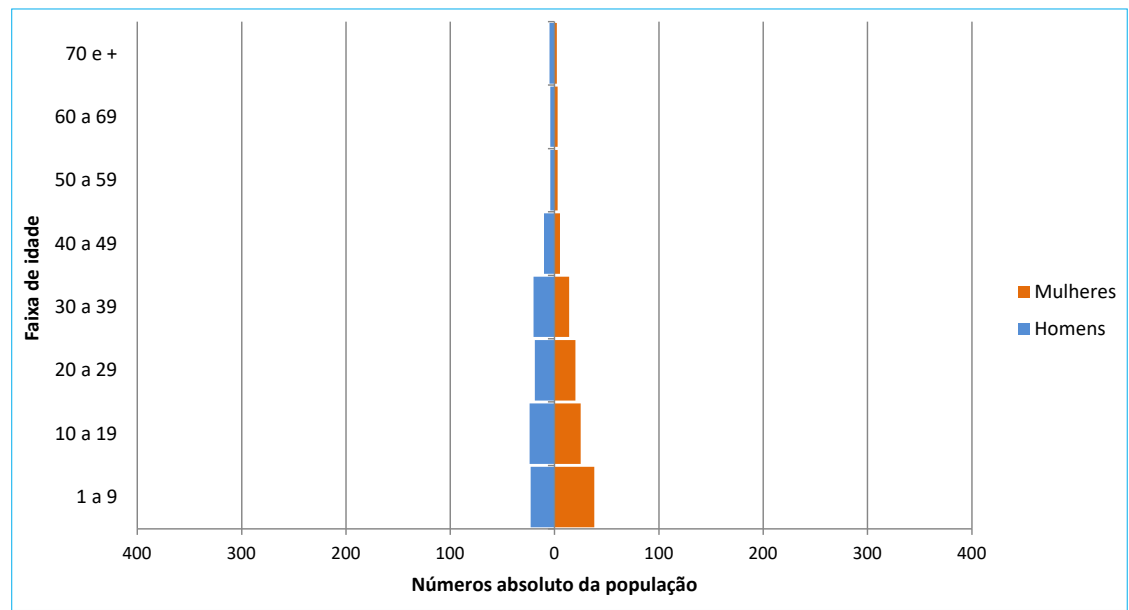

Gráfico 2 - Pirâmide etária da população escrava. Campinas: 1790

Fonte: Listas Nominativas de Campinas (AEL - UNICAMP).

O Gráfico 2 evidencia que a faixa de crianças ( 1 - 9 anos) do sexo feminino sobressaía diante das demais, uma constante verificada nas Listas Nominativas analisadas desde 1778 até 1794 . Esse perfil da população infantil na estrutura demográfica de Campinas assemelha-se ao encontrado por Motta (1999, p. 230, 278) para o caso de Bananal em 1801. Embora seja difícil estabelecer algumas respostas para tais situações, alguns paralelos podem ser traçados em relação às crianças cativas. O primeiro deles se refere ao tamanho das propriedades em que viviam essas pessoas, pois a maioria encontrava-se naquelas que possuíam um maior número de cativos, favorecendo a constituição de famílias sob o cativeiro diante daquilo que propunham As Constituições do Arcebispado da Bahia. Dessa maneira, é possível inferir que o maior número de crianças pode estar relacionado, por um lado, a uniões legítimas ou legitimadas pela Igreja e, por outro, ao nascimento de naturais entre os sujeitos escravizados, frutos de relações sexuais entre eles.

Um segundo ponto está vinculado justamente "ao efeito que o desenvolvimento dessas famílias poderia ter sobre o próprio tamanho dos plantéis onde elas estivessem. (...) ao que tudo indica, a família escrava responde pela transformação de um plantel médio em um grande" (MOTTA, 1999, p. 279-280). Situação semelhante ocorreu em Campinas até 1790, podendo dizer que havia um equilíbrio entre os sexos dos cativos, especialmente daqueles que se encontravam na faixa de 10 a 29 anos; porém, a partir de 1794, o interesse dos senhores passou a ser em comprar homens de 20 a 29 anos, como observamos no Gráfico 3. Sem dúvida, a lavoura canavieira mudou o comportamento dos escravistas em relação ao tipo de escravo a ser adquirido, com 
o ingresso de homens jovens e adultos provenientes em sua maioria da Guiné, mas também de Angola, Moçambique e do Congo.

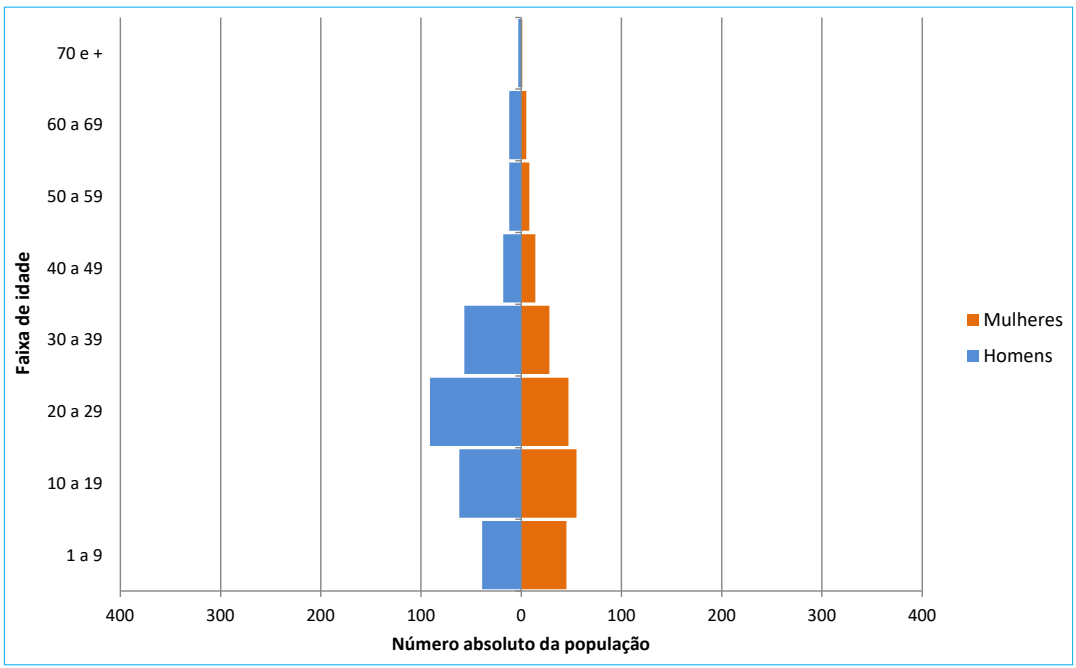

Gráfico 3 - Pirâmide etária da população escrava. Campinas: 1794 Fonte: Listas Nominativas de Campinas (AEL - UNICAMP).

Assim, em 1778, o Sargento-mor João Rodrigues da Cunha mantinha, em seu domicílio, três famílias de escravos, Matheus e Maria, juntamente com dois filhos, José, 42 anos, casado com Thereza, forra, ao lado de quatro filhos, e mais Francisco e Ana, com três filhos. Além destes, o Sargento tinha mais quatro escravos, totalizando 18 indivíduos. Alguns anos depois, em 1782, o grupo de cativos do Sargento modificara-se um pouco, pois ele não possuía mais os quatro últimos escravos, e a escrava Maria, mulher de Matheus, havia morrido naquele ano; porém, graças às famílias escravas, o número de cativos mantinha-se o mesmo. ${ }^{14}$

O Gráfico 3, por seu turno, apresentou uma configuração em que o desequilíbrio entre os sexos dos escravos começou a ser verificado, especialmente nas faixas adultas de 10 a 39 anos, com a preferência pelo trabalho masculino. Para Slenes (1999, p.75), esse quadro provocou a falta de parceiros entre os cativos, de tal modo que é possível que a expansão da família escrava tenha sofrido uma redução no número de casais, embora não obstruindo a existência da mesma. O fato é que esse processo de acumulação de capitais na forma de mão de obra africana se tornou tão presente na vila campineira, sobretudo entre as propriedades monocultoras, voltadas ao mercado externo, que os dados extraídos do Mapa Geral de habitantes para o ano de 1806 revelaram essa tendência, ou seja, a preferência pela compra de cativos jovens e 
adultos do sexo masculino, tendência que prevaleceu até a segunda metade do século $\mathrm{XIX}$, quando o tráfico internacional de escravos foi proibido no Brasil.

Até 1850, o fluxo demográfico de africano será constante pela necessidade de reposição contínua de escravos, em consequência do alto nível de mortalidade dessa população. Após a proibição do tráfico há outro deslocamento demográfico de escravos desta vez em direção às áreas prósperas do sudeste e Minas que começam a comprá-los, através do tráfico interprovincial (MOURA, 1994, p. 147).

Vejamos o Gráfico 4:

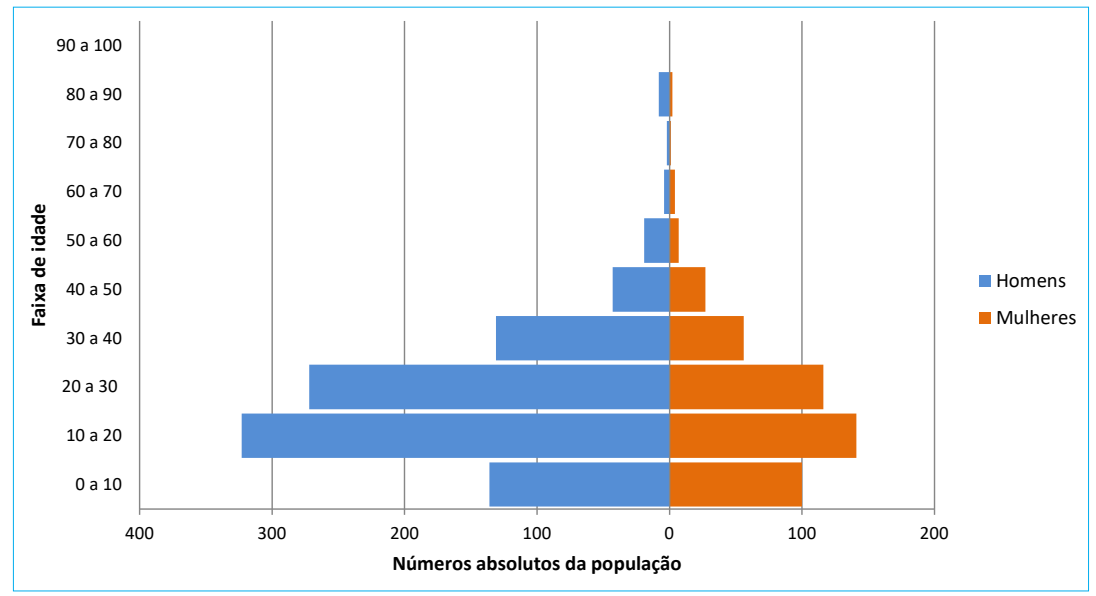

Gráfico 4 - Pirâmide etária da população escrava. Campinas: 1806 Fonte: Mapa Geral dos Habitantes de Campinas (Arquivo Edgard Leuenroth - UNICAMP).

Na passagem do século XVIII para o XIX, a América Portuguesa apresentou uma configuração demográfica inaudita entre as colônias americanas: uma parte da população negra e de descendentes africanos, livres, convivia com brancos, enquanto havia uma maioria escravizada de africanos e um número representativo de pardos e crioulos nascidos na colônia, que apresentava uma proporção populacional composta por $28 \%$ de brancos, $27,8 \%$ de negros e mulatos livres, $38,5 \%$ de negros e pardos escravizados, e 5,7\% de indígenas. Esses dados, que Marquese (2006, p.118) apresentou de Marcílio (1999, p. 321), serviram para reafirmar que a "gênese dessa grande população livre negra e mulata se deu, fundamentalmente, pela dinâmica do tráfico transatlântico de escravos acoplada à dinâmica da alforria".

O que o Gráfico 4 revela é a passagem em que a população escravizada em Campinas, vinda sobretudo da África, passou a ter um peso maior no conjunto da população total. Basta dizer que em 1798 a população livre branca era composta por 54\%, vindo a cair para 44\% em 1806 e 35\% em 1814, ao passo que a população livre e 
mulata em 1798 era de $17 \%$, subindo para $25 \%$ em 1806 e reduzindo para $24 \%$ em 1814 . A população preta e escravizada em 1798 era de 24\%, subindo seu número para 26\% da população em 1806, e chegando a 39\% em 1814. Essa tendência de aumento da população debaixo do cativeiro continuou a aumentar até que em 1829 seu número ultrapassou a população livre, incluindo aí os brancos e mulatos (TEIXEIRA, 2017, p. 577). Um dos resultados desse desequilíbrio foi a tentativa de rebelião escrava em 1832 ocorrida entre algumas das grandes propriedades escravistas de Campinas, que foi muito bem estudada por Pirola (2005).

Os dados apresentados na Tabela 10 para a faixa de pequenas posses de cativos nos levam a concordar com a ideia de que uma grande barreira aos casamentos religiosos entre escravos era o pequeno rol de potenciais cônjuges. Por outro lado, entre as propriedades com 10 ou mais escravos, a razão de sexo pode determinar a proporção de homens e mulheres casados. Para o ano de 1778, notamos o predomínio do elemento feminino entre os cativos (nas posses com 10 ou mais escravos), favorecendo não só o casamento para os homens como também possibilitando a oportunidade de escolha de seu cônjuge. Este caso pode demonstrar como um dado sistema demográfico está associado à sua base econômica, podendo gerar a alteração em uma determinada variável demográfica, como o sexo. Assim, procuramos mostrar que a entrada da lavoura canavieira em Campinas alterou a estrutura demográfica do contingente cativo que, forçadamente, foi instalando-se na região.

Tabela 10 - Casados e viúvos como porcentagem dos escravos e escravas de 15 anos ou mais, por tamanho de faixa de cativos. Campinas, 1778, 1801, 1829.

\begin{tabular}{lccccccccc}
\hline \multirow{2}{*}{$\begin{array}{l}\text { Tamanho } \\
\text { de Faixa de } \\
\text { Plantel }\end{array}$} & \multicolumn{2}{c}{$\begin{array}{c}\text { Homens } \\
\text { com } \mathbf{1 5} \text { anos ou mais }\end{array}$} & \multicolumn{2}{c}{$\begin{array}{c}\text { Mulheres } \\
\text { com } \mathbf{1 5} \text { anos ou mais }\end{array}$} & \multicolumn{2}{c}{$\begin{array}{c}\text { Razão de Sexo } \\
\text { entre a população com } \\
\mathbf{1 5} \text { anos ou mais }\end{array}$} \\
\cline { 2 - 11 } & $\mathbf{1 7 7 8}$ & $\mathbf{1 8 0 1}$ & $\mathbf{1 8 2 9}$ & $\mathbf{1 7 7 8}$ & $\mathbf{1 8 0 1}$ & $\mathbf{1 8 2 9}$ & $\mathbf{1 7 7 8}$ & $\mathbf{1 8 0 1}$ & $\mathbf{1 8 2 9}$ \\
\hline $1-9$ & $19,2 \%$ & $32,8 \%$ & $20,0 \%$ & $31,2 \%$ & $39,2 \%$ & $31,4 \%$ & 163 & 123 & 170 \\
10 e + & $58,3 \%$ & $29,3 \%$ & $23,4 \%$ & $42,8 \%$ & $68,8 \%$ & $60,2 \%$ & 86 & 231 & 309 \\
\hline Total & $31,5 \%$ & $30,1 \%$ & $23,0 \%$ & $36,6 \%$ & $58,2 \%$ & $55,4 \%$ & 126 & 192 & 286 \\
\hline
\end{tabular}

Fonte: Listas Nominativas de Campinas (AEL - Unicamp), 1778. Os dados para 1801 e 1829 foram coletados em SLENES, 1998, p. 75, Tabela 1.

\section{Considerações finais}

Os preços do açúcar estimularam o povoamento em Campinas, mas só "no final da década de 1790", garantiu Eisenberg (1989, p. 347); portanto, os habitantes que se instalaram antes desse momento eram, principalmente, pessoas que se fixaram com o apoio familiar antes dos preços do açúcar começar a subir. Até 1814, esse processo de povoamento, baseado na migração de pessoas oriundas de localidades diversas mas próximas, favoreceu o crescimento da população livre de um modo geral. A partir do momento em que esse processo sofreu um arrefecimento, a população livre não acompanhou o aumento da população escrava, que a ultrapassou em 1829. Essas ideias sugerem que, enquanto havia terras disponíveis e de fácil acesso às populações de 
outros lugares, estas, incentivadas por parentes ou amigos, vinham e se instalavam, contribuindo, assim, para o crescimento de livres. Porém, nos anos que sucederam 1814, em que as grandes fazendas passaram a ocupar cada vez mais espaço para ampliar sua produção, a importação de escravos se fez mais necessária, e daí notamos a estabilização da população presente nos domicílios sem escravos, portanto livre.

A partir da primeira década do século XIX, a economia açucareira instalada em Campinas determinou uma mudança profunda no perfil demográfico, importando mais escravos e dificultando a entrada do contingente populacional livre de pardos e brancos pobres, que passaram a ir mais para o Oeste, onde as terras de boa qualidade, acompanhadas de outros estímulos, atraíam os novos moradores. Assim, lugares como Piracicaba, Rio Claro, Araraquara e outros devem ter sofrido processo colonizador semelhante (DEAN, 1977, p. 27, 32, 33, 36, 40, 183). Podemos assinalar que a população livre cresceu rapidamente entre o final do século XVIII até os anos de 1808 quando o ritmo diminuiu, e por outro lado que a população escrava, que também veio crescendo significativamente desde 1798, a ultrapassou após 1822. Essas transformações representaram o advento dos grandes engenhos, pois em 1829 essas propriedades contavam com mais de 40 escravos e representavam a posse de $55,5 \%$ dos cativos. Além do mais, essas grandes fazendas escravistas se caracterizaram pela predominância de homens, em sua maioria africanos e jovens (a razão de sexo média foi de 234).

A Lista Nominativa de 1829 permitiu conhecer os grandes senhores de engenho. Esta elite agrária provinha de localidades vizinhas que, a exemplo de Itu e Jundiaí, encaminhavam seus filhos para Campinas a fim de adquirirem terras, estabelecerem engenhos e multiplicar suas rendas. Ao estudar a produção dos engenhos bem como a população cativa que neles trabalhava, percebemos a alta taxa de concentração dessas formas de riqueza nas mãos de uma minoria. Somente diante dessas informações podemos entender as elevadas médias de escravos por escravistas, bem como a crescente concentração de cativos nas mãos de uma elite que se engrandeceu com o açúcar.

Finalmente, esse artigo deu ênfase ao ciclo açucareiro procurando revelar a contribuição do mesmo no processo colonizador do interior paulista, com foco no estudo de caso que tratou dos primórdios da fundação de Campinas até os anos de 1830. Pensar as mudanças operadas em Campinas a partir da elevação à sua condição de cidade, em 1842, revela outra realidade talvez mais complexa, uma vez que a mesma começou a abrigar em seu território, imigrantes europeus, alemães e portugueses no princípio, como também italianos, espanhóis e muitos outros grupos, que passaram a conviver com a população livre, liberta e cativa. No entanto, esse processo de colonização da segunda metade do século XIX teve, não apenas em Campinas mas em todo o Oeste de São Paulo, o café como mola propulsora da economia. 


\section{Referências}

BACELLAR, Carlos de Almeida Prado. As listas nominativas de habitantes da capitania de São Paulo sob um olhar crítico (1765-1836). Anais de História de Além-Mar, v. XVI, p. 313-338, 2015.

Os senhores da terra: Família e sistema sucessório entre os senhores de engenho do Oeste paulista, 1765-1855. Campinas: Área de Publicações CMU/ Unicamp, 1997.

BELLOTTO, Heloísa L. Autoridade e conflito no Brasil colonial: o governo do Morgado de Mateus em São Paulo (1765 - 1775). São Paulo: Sec. Est. da Cultura, 1979.

BUENO, Beatriz P. Siqueira. Dilatação dos confins: caminhos, vilas e cidades na formação da Capitania de São Paulo (1532-1822). Anais do Museu Paulista. São Paulo, v. 17, n. 2, p. 251-294, 2009.

CAMPOS, Alzira Lobo de A. A configuração dos agregados como grupo social: marginalidade e peneiramento (o exemplo da cidade de São Paulo no século XVIII). Revista de História, São Paulo, n. 17, p. 27-69, 1984.

COSTA, Dora Isabel P. da. Herança e ciclo de vida: um estudo sobre a família e população em Campinas, São Paulo (1765-1850). Niterói. Tese (Doutorado em História). Universidade Federal Fluminense, 1997.

COSTA, Iraci del Nero. Minas Gerais: estruturas populacionais típicas. São Paulo: EDEC, 1982.

DEAN, Warren. Rio Claro: um sistema brasileiro de grande lavoura, 1820-1920. Rio de Janeiro: Paz e Terra, 1977.

EISENBERG, Peter L. Homens esquecidos: escravos e trabalhadores livres... Campinas, S.P.: Ed. da Unicamp, 1989.

FULLER, Cláudia M. Pequenos agricultores numa economia açucareira e exportadora (Campinas, 1820-1840). Dissertação (Mestrado) - Instituto de Filosofia e Ciências Humanas (IFCH), Universidade Estadual de Campinas (Unicamp), Campinas, 1995.

KIDDER, Daniel P. Reminiscências de viagens e permanências nas províncias do Sul do Brasil. Belo Horizonte: Ed. Itatiaia; São Paulo: Ed. da USP, 1980.

KUZNESOF, Elizabeth A. The puzzling contradictions of child labor, unemployment, and education in Brazil. Journal of Family History, v. 23, n.3, p. 225-239, 1998.

LEMOS BRITO, José G. de. Pontos de partida para a história econômica do Brasil. 3a. ed. São Paulo: Nacional; Brasília: INL, 1980.

LISANTI FILHO, Luís. Negócios coloniais (uma correspondência comercial do século XVIII). Brasília: Ministério da Fazenda; São Paulo: Visão, 1973.

LUNA, Francisco Vidal. Minas Gerais: escravos e senhores. São Paulo: IPE/USP, 1981. 
LUNA, F. V.; KLEIN, H. Escravos e senhores no Brasil no início do século XIX: São Paulo em 1829. Estudos Econômicos, São Paulo, v. 20, n. 3, p. 349-379, 1990.

MARCÍLIO, Maria Luiza. Crescimento demográfico e evolução agrária paulista: 17001836. São Paulo: Hucitec, Edusp, 2000.

MARCONDES, Renato L. Desigualdades regionais brasileiras: Comércio marítimo e posse de cativos na década de 1870. Ribeirão Preto. Tese de Livre-docência. Universidade de São Paulo, 2005.

A arte de acumular na economia cafeeira: Vale do Paraíba, século XIX. Lorena, S.P.: Editora Stiliano, 1998.

MARQUESE, R. B. Dinâmica da escravidão no Brasil: resistência, tráfico negreiro e alforrias, séculos XVII a XIX. Novos Estudos CEBRAP, São Paulo, v. 1, n. 1, p. 107-123, 2006.

MARTINS, Valter. Nem senhores, nem escravos: os pequenos agricultores em Campinas; 1800-1850. Campinas: Área de Publicações CMU/UNICAMP, 1996.

MESQUITA, Eni de. O papel do agregado na região de Itu - 1780 a 1830. São Paulo: Fundo de Pesquisas do Museu Paulista da USP, 1977 (Coleção Museu Paulista, série História, v. 6).

MILLER, Shawn W. A madeira combustível na Bahia colonial: conseqüências sociais e econômicas da escassez de combustível, 1549-1820. Estudos Econômicos, São Paulo, v. 25 , n. 1, p. 115-145, 1995.

MOTTA, José Flávio. Corpos escravos, vontades livre: posse de cativos e família escrava em Bananal (1801 - 1829). São Paulo: FAPESP: Annablume, 1999.

; NOZOE, Nelson. Cafeicultura e acumulação. Estudos Econômicos, São Paulo, v. 24, n. 2, p. 253-320, 1994.

MOURA, C. Dialética radical do Brasil negro. São Paulo: Editora Anita, 1994.

MÜLLER, Daniel Pedro. Ensaio dum quadro estatístico da Província de São Paulo. São Paulo: Governo do Estado, 1978.

PETRONE, Maria T. S. A lavoura canavieira em São Paulo. São Paulo: Difel, 1968.

PIROLA, R. F. A conspiração escrava de Campinas, 1832: rebelião, etnicidade e família. Dissertação (Mestrado) - Instituto de Filosofia e Ciências Humanas (IFCH), Universidade Estadual de Campinas (Unicamp), Campinas, 2005.

SAINT-HILAIRE, Auguste de. Viagem à Província de São Paulo. Belo Horizonte: Ed. Itatiaia; São Paulo: Ed. da USP, 1976.

SLENES, Robert W. Na senzala, uma flor: esperança e recordações na formação da família escrava, Brasil Sudeste, século XIX. Rio de Janeiro: Nova Fronteira, 1999. 
A formação da família escrava nas regiões de grande lavoura do Sudeste: Campinas, um caso paradigmático no século XIX. População e Famillia, São Paulo, v. 1, n. 1, p. 9-82, 1998.

TEIXEIRA, Paulo E. Campinas, uma vila colonial (1774-1822). Revista Brasileira de Estudos de População, Belo Horizonte, v. 34, n. 3, p. 567-591, 2017.

O outro lado da familia brasileira. Campinas, SP: Editora da Unicamp, 2004.

WEECH, Friedrich Von. A agricultura e o comércio do Brasil no sistema colonial. São Paulo: Martins Fontes, 1992.

\section{Notas}

1 Sobre as Listas Nominativas de habitantes e seu potencial para pesquisa histórica, veja os seguintes textos: BACELLAR, 1997, p. 33-36; BACELLAR, 2015.

${ }^{2}$ Fogo é o termo encontrado nas Listas Nominativas de habitantes e para esse trabalho designa o domicílio. Para uma discussão mais ampla sobre o termo, consulte Teixeira (2004, p. 49-50).

${ }^{3}$ Fonte: Lista Nominativa de Campinas, 1797, Cia 1, fogo 1; 1799, Cia 1, fogo 1; 1800, Cia 1, fogo 1. (Fundo Peter Eisenberg - Arquivo Edgard Leuenroth/UNICAMP)

4Fonte: Lista Nominativa de Campinas, 1803, Cia 2, fogo 53; 1804, Cia 1, fogo 7; 1814, Cia 6, fogo 23; 1829, Cia 6, fogo 6. (Fundo Peter Eisenberg - Arquivo Edgard Leuenroth/UNICAMP)

${ }^{5} \mathrm{~A}$ medida correspondente para o alqueire diverge entre alguns autores: para Lisanti Filho (1973, pp.79-94) é de 13,8 litros; para Friedrich Von Weech (1992, p. 58) corresponde a 13 litros; e José Lemos Brito (1980, p. 352-355) assegura que seu valor é de 36,36 litros.

6 Fonte: Lista Nominativa de Campinas, 1814, Cia 2, fogo 6. (Fundo Peter Eisenberg - Arquivo Edgard Leuenroth/UNICAMP)

7 peso adotado para a conversão da arroba foi de 14,7kg, aceito por Lisanti Filho (1973, p. 79-94) e Lemos Brito (1980, p. 352-355), uma vez que para Weech (1992, p. 58) a arroba corresponde a $11,67 \mathrm{~kg}$.

8Fonte: Lista Nominativa de Campinas, 1829, Cia 6, fogos 84, 33 e 70, respectivamente. (Fundo Peter Eisenberg - Arquivo Edgard Leuenroth/UNICAMP)

9 Nesse estudo de diversas localidades mineiras do início do século XIX, o autor propõe quatro categorias para a classificação de localidades: Urbana, Intermédia, Rural de Autoconsumo e RuralMineradora. Embora o nosso estudo seja de apenas uma sociedade, o longo período permitiu visualizar, pelo menos, duas estruturas bem distintas em Campinas: Rural de Autoconsumo e Rural-Mineradora.

10 Luna e Klein, estudando a posse de escravos em algumas localidades de São Paulo em 1829, apontaram para as seguintes médias de escravos por proprietário: Itu = 11,0; Mogi = 4,6; São Paulo $=4,9$. Em Campinas, nesse ano a média foi de 14,7. Cf. Escravos e senhores no Brasil no início do século XIX: São Paulo em 1829. Estudos Econômicos, São Paulo, v.20, n.3, 1990, p. 370.

$11 \mathrm{Em} 1774$ havia 5 sítios "por carta de venda", apenas 8 por "escritura”, 7 em "terras devolutas", 9 "sitio em posse", e 10 "sitio a favor", o que sinaliza para a precariedade de títulos de propriedade da terra, tendo em vista que a primeira lei que veio a regulamentar a compra e venda de terras no Brasil é de 16 de setembro de 1850. 
12 "O índice de Gini corresponde a um coeficiente estatístico largamente utilizado para medir concentração de renda e riqueza. (...) quanto mais regularmente se distribui a renda ou riqueza, mais próximo de zero estará o valor do índice (zero no limite); correlativamente, quanto mais concentrada estiver a riqueza ou renda, maior será o valor do aludido índice que, no máximo, iguala-se à unidade." (LUNA, 1981, p. 121, nota n. ${ }^{4}$ ). Utilizamos a variável "posse de escravos" como uma proxy da variável "riqueza".

${ }^{13}$ As Listas de 1767 e 1770 não registraram nenhum escravo, e a de 1774 apenas indica o número total de cativos em um fogo. Os dados para os anos de 1800, 1817 e 1829, foram coletados em MARTINS (1996, p.32-34), e em virtude disso as informações para a faixa abaixo de 12 anos corresponde na realidade à faixa de até 9 anos, ao passo que a faixa seguinte corresponde de 10 a 59.

${ }^{14}$ Fonte: Lista Nominativa de Campinas, 1778, fogo 5, e 1782, fogo 4.

\section{Nota do Editor}

A revista História (São Paulo) agradece à FAPESP pelo apoio financeiro, na modalidade Auxílio à Pesquisa - Publicações/Periódicos (Processo n. 2020/04324-9), para a publicação deste artigo.

Paulo Eduardo TEIXEIRA é bacharel e licenciado em História pela UNICAMP, com mestrado em História Social pela UNESP/Franca, doutorado em História Econômica pela USP, e recentemente concluiu o pós-doutorado em Sociologia pela UFSCar. Desde 2006 é professor de História do Brasil nos cursos de Ciências Sociais e Relações Internacionais da UNESP/Marília, e participa do Programa de Pós-graduação em Ciências Sociais da mesma instituição. As áreas de interesse abrangem temas relacionados à sociedade brasileira do século XIX, como família, escravismo e processos migratórios, em uma perspectiva interdisciplinar. É autor dos livros O outro lado da família brasileira (Campinas: Editora da Unicamp, 2004), e A formação das familias livres em Campinas (São Paulo: Editora Unesp, 2011), além de ser um dos organizadores do livro Migrações: Implicações passadas, presentes e futuras. (Marília; São Paulo: Oficina Universitária; Cultura Acadêmica, 2012). 